\title{
How Does the Arctic Council Support Conservation of Arctic Biodiversity?
}

\author{
Tom Barry ${ }^{1, * \mathbb{D}}$, Brynhildur Daviðsdóttir ${ }^{2}$, Níels Einarsson ${ }^{3}$ and Oran R. Young ${ }^{4}$ \\ 1 Environment and Natural Resources, University of Iceland, 102 Reykjavík, Iceland \\ 2 Environment and Natural Resources, Department of Economics and Department of Life and Environmental \\ Sciences, University of Iceland, 102 Reykjavík, Iceland; bdavids@hi.is \\ 3 Stefansson Arctic Institute, 600 Akureyri, Iceland; ne@svs.is \\ 4 Bren School of Environmental Science and Management, University of California, \\ Santa Barbara, CA 93103, USA; young@bren.ucsb.edu \\ * Correspondence: tom@caff.is; Tel.: +354-861-9824
}

Received: 7 May 2020; Accepted: 16 June 2020; Published: 20 June 2020

check for updates

\begin{abstract}
The Arctic Council is an intergovernmental forum promoting cooperation, coordination and interaction among Arctic states, indigenous communities, and peoples on issues of common importance. The rising geo-political importance of the Arctic and the onset of climate change has resulted in the Council becoming a focus of increasing interest from both inside and beyond the Arctic. This has resulted in new demands placed on the Council, attracting an increasing number of participants, and instigating a period of transformation as Arctic states work to find a way to balance conflicting demands to improve the Council's effectiveness and take care of national interests. This paper considers whether, during this time of change, the Council is having an impact on the issues it was formed to address, i.e., environmental protection and sustainable development. To provide answers, it looks at how the Council reports on and evaluates progress towards the implementation of recommendations it makes regarding biodiversity, how it identifies where activities have had impacts and uncovers the mechanisms through which they were successful, to provide an insight into how the Arctic Council can be an agent of change.
\end{abstract}

Keywords: Arctic; Arctic Council; CAFF; biodiversity; conservation; conservation of Arctic flora and fauna; Arctic biodiversity assessment; institutional effectiveness

\section{Introduction}

Arctic biodiversity is under serious threat from climate change [1] and, with temperatures increasing by more than double the global average over the last two decades [2], this is expected to drive widespread changes in its wildlife [3-5]. Large tracts of the Arctic, however, remain relatively undisturbed, providing a unique opportunity for proactive action that can minimize or even prevent future problems that would be costly, or impossible, to reverse [1]. In response, there is an urgent need to speed up and scale up actions to ensure Arctic biodiversity conservation. This includes the implementation of relevant Arctic Council recommendations, as well as commitments under international agreements relevant to the Arctic, such as the Aichi Biodiversity Targets under the United Nations Convention on Biological Diversity (CBD) [6].

The Arctic Council is an intergovernmental forum promoting cooperation, coordination, and interaction among Arctic States, with the involvement of Arctic indigenous communities and other Arctic inhabitants [7]. It is a consensus forum with no ability to enforce its guidelines, advice or recommendations, which remain the responsibility of member states The Arctic Council is comprised of eight member states (Canada, the Kingdom of Denmark (including Greenland and the Faroe 
Islands), Finland, Iceland, Norway, Russia, Sweden and the United States) and six indigenous organizations known as Permanent Participants (Aleut International Association, Arctic Athabaskan Council, Gwich'in Council International, Inuit Circumpolar Council, Russian Association of Indigenous Peoples of the North, Saami Council). The Permanent Participants sit at the same table as the member States and can intervene and speak according to the same procedures applied to member States. The Arctic States are obliged to consult them on all the Council's negotiations and decisions but ultimately it is the Arctic States who are the final decisions makers [8]. In addition, the Council also has the category of Observers which currently consists of 13 Non-arctic States, 13 Intergovernmental and Inter-Parliamentary Organizations and 12 regional and Non-governmental Organizations. There are six Working Groups where the majority of the Council's work is undertaken: the Arctic Contaminants Action Program (ACAP), Arctic Monitoring and Assessment Programme (AMAP), Conservation of Arctic Flora and Fauna (CAFF), Emergency Prevention, Preparedness and Response (EPPR), Protection of the Arctic Marine Environment (PAME) and the Sustainable Development Working Group (SDWG).

While the Council is not a Multi-Lateral Environmental Agreement (MEA) it reflects many of their concerns, e.g., through efforts to ensure synergies, create more effective governance and set priorities leading to the development of legally binding agreements [9]. The importance of linkages between the Council and MEAs that touch on the Arctic can be seen in how its activities inform the work of MEAs and in some cases contribute towards their formation. For example, the work of its subsidiary bodies has led to recognition by the UN Convention of Biological Diversity (CBD) of Arctic biodiversity as an emerging issue [10] and subsequent reporting to the CBD on the status of Arctic biodiversity (e.g., [11]); every 4 years, an analysis of data on the reduction in Persistent Organic Pollutant emissions for the Arctic is conducted by the Council in support of article 4 of the Stockholm Persistent Organic Pollutants Convention; and the Council's work on shipping contributed to the development of the International Code for Ships Operating in Polar Waters (Polar Code) [12].

The Council, however, has no overall strategy to guide its activities or evaluate any impact its activities may have to help ascertain if its goals are being achieved, hindering its ability to address broader issues such as climate change and sustainable development [9]. While the Council as a whole does not yet have a strategic plan, each of its Working Groups have strategic documents defining overarching goals [13-18]. However, only two specify in detail the actions needed to achieve these goals, i.e., the Actions for Arctic Biodiversity 2013-2021: implementing the recommendations of the Arctic Biodiversity Assessment (Actions for Arctic Biodiversity) [15] and the Arctic Marine Strategic Plan 2015-2025 (AMSP) [17], thereby providing a reporting mechanism and a potential framework to facilitate the evaluation of the effectiveness of the Council [9]. The absence of obligated reporting as to how Arctic states are following up on the implementation of the Council's recommendations also lends itself to a lack of transparency as to how, or if, states act on outcomes from the Council's work, meaning that while the Council's impacts on a global scale are visible, detecting the effects of the Council's work at national or sub-national levels is difficult. While reporting by Arctic states is voluntary, observer states and organisations are required to submit reports every four years on their contributions to the work of the Council [8].

It is within this context that this paper considers whether, during this time of change, the Council is having an influence on the issues it was formed to address, i.e., environmental protection and sustainable development. To provide answers it focuses on biodiversity as one aspect of its work which touches on both goals and looks at how the Council reports on and evaluates progress towards the implementation of recommendations it makes regarding biodiversity. It identifies where activities have had impacts and uncovers mechanisms through which they were successful, to provide insight into how the Arctic Council can be an agent of change. In order to do so, it looks at the creation and implementation of the first circumpolar assessment of the Arctic's biodiversity, the Arctic Biodiversity Assessment (ABA) [19], asks whether it has made a difference to the conservation of Arctic biodiversity and, if so, how this was achieved. Attempting to answer these questions entails considering the process 
of developing the ABA and the use of its subsequent implementation plan [15] as a framework to analyse how the Council is following up on these recommendations.

\section{Materials and Methods}

To provide a baseline to inform this analysis, a database was created detailing actions taken by the Arctic Council in response to ABA recommendations [1]. This baseline was informed by a series of meetings to evaluate the status of the implementation of biodiversity actions in the Arctic Council, delivered to the Foreign Ministers of the Arctic States in 2017 and 2019 in the form of reports on progress towards the implementation of the ABA recommendations [20,21]. Methods used to inform the analysis include reviews by bureaucrats, experts and programme staff with a long history of engagement in the Council, both as state and indigenous representatives, participation in numerous Arctic Council meetings between 2008-2020, and a review of Arctic Council meeting documents from 1996-2020.

\section{Results}

\subsection{Arctic Council}

Arctic Council members are committed to consensual decision making and, as an organization, it lacks the resources and often the mandates to engage directly in implementation. Despite this lack of formal authority and resources, the Council can influence the behaviour of member states and organisations, e.g., through knowledge building, capacity enhancement, facilitating dialogue and transferring information or advice to decision makers. However, the lack of obligated reporting on national follow-up can make it difficult to discern when Council actions have led to or influenced an effective response [8], and challenging to trace the pathways via which this may have happened, e.g., through nudging movements by decision makers towards desired outcomes. Furthermore, progress towards achieving a goal may also be due to a combination of multiple causal factors, such as the timing and prominence of the issue to the state in question, contributing to the difficulty in tracing the roles a Council activity might have played in ensuring a specific outcome. Therefore, identifying where Council activities have had impacts and uncovering the mechanisms through which they were successful may provide an insight into how the Council can be an agent of change.

Research on the Council has largely focused on approaches to how its organisational effectiveness might be evaluated [22] and the role its structure plays [23-25]. While environmental cooperation has received some attention (e.g., [26-29]), consideration of the Council's work on biodiversity is, with a few exceptions, absent from the literature (e.g., [21-24]). Notable exceptions include the World Wildlife Funds (WWF) Arctic Council Scorecards [30,31], which attempt to measure how state governments are responding to key Council recommendations. This analysis includes a biodiversity category, where in 2017 efforts by the Council and Arctic states were assigned grades of $C$ or D meaning either some or little progress on implementation while in 2019 only Sweden scored higher with a grade of B meaning encouraging progress towards implementation. While the scorecards shed light on the need for both Arctic Council and state action to demonstrate Council effectiveness, they do not establish causality, e.g., identify clear links between a State's actions and a Council recommendation. The use of different approaches used in the scorecards also makes comparisons between them difficult and the 2019 scorecard does not provide an assessment of the Councils overall implementation [32].

The Arctic Council has made some efforts to improve how it reports on what it does and, in 2015, it introduced the Amarok tracking tool [33] intended to report on the status, duration and leads of an activity. However, this tool is of limited use as it fails to capture the level of detail and actions found in strategies such as the Actions for Biodiversity. A promising development are efforts by the Conservation of Arctic Flora and Fauna (CAFF) and the Protection of the Arctic Marine Environment (PAME) Working Groups to align reporting on the implementation of the AMSP [17] and the Actions for Biodiversity [15], offering a potential step towards a broader and more detailed reporting model within the Council. 


\subsection{Arctic Council and Biodiversity}

While aspects of biodiversity are touched upon across several of the Council's subsidiary bodies, the CAFF Working Group is the primary instrument through which the Council addresses biodiversity [9] with a mandate to address the conservation of Arctic biodiversity, and to communicate its findings to the governments and residents of the Arctic, helping to promote practices which ensure the sustainability of the Arctic's living resources [34]. It does so through monitoring what is happening to Arctic biodiversity, assessing changes detected and, based on the outcomes from these activities, developing policy recommendations and management advice designed to contribute towards informed decision making (Figure 1).

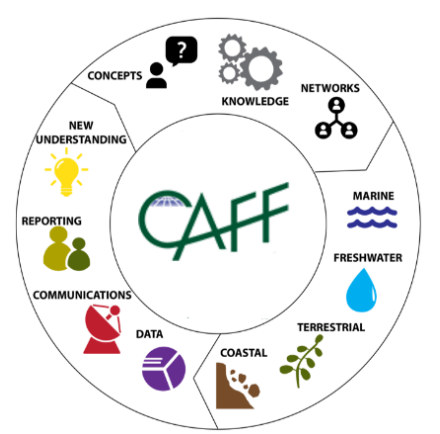

Figure 1. Conceptual framework for how Conservation of Arctic Flora and Fauna (CAFF) operates.

CAFF also reports on Arctic biodiversity through a framework of agreements with global conventions and initiatives relevant for Arctic biodiversity [35-41]. One example of how an Arctic Council report can directly inform and support decisions relating to global biodiversity frameworks is demonstrated by the release of the Arctic Biodiversity Trends 2010: Selected Indicators of Change report [42], which led to recognition by the Convention of Biological Diversity (CBD) of Arctic biodiversity as an emerging issue [43] and an invitation to the Arctic Council to provide information and assessments on Arctic biodiversity [44]. While CAFF has delivered information to the CBD (e.g., [45]), Arctic states have so far made limited use of CAFF products in national reporting to the CBD. However, there are exceptions, with Canada, for example, using data from the first component of the ABA, the Arctic Biodiversity Trends 2010: Selected Indicators of Change report and CAFF's Arctic Species Trend Index (ASTI) [46] to inform on the status and trends of Arctic ecosystems and species in its 2014 national report to the CBD [47]. Information is also provided to the Intergovernmental Science-Policy Platform on Biodiversity and Ecosystem Services (IPBES), but without an agreement to guide this cooperation, it has been less coordinated than, e.g., with the CBD. Climate change is the most serious threat to Arctic biodiversity, driving a broad range of stressors on biodiversity [1] and its relative failure is a key factor impacting Arctic biodiversity, e.g., in determining the fate of polar bears. Links between the Council and the United Nations Framework Convention on Climate Change (UNFCCC) reflect the thematic structure of how the Council's subsidiary bodies are coordinated via the AMAP Working Group, which deals with pollutants and climate change.

As a bridging organization in the divide between science and policy, CAFF is accountable to both worlds, as can be seen through the abovementioned framework of agreements. However, few studies have considered its role in any detail (e.g., [48]) or the outcomes of its activities (e.g., [8,49,50]). Research that considers CAFF has largely done so peripherally in the context of the structure and operation of the Council (e.g., [51]) rather than through an analysis of its role or the impact of its activities.

\subsection{Assessing the Status and Trends of Arctic Biodiversity}

The ability to develop effective management advice and policy recommendations on Arctic biodiversity requires a baseline to provide an understanding of status, trends and gaps in knowledge. In 2001 CAFF provided the first circumpolar overview of Arctic biodiversity, identifying key 
conservation issues and relationships, and the actions needed to achieve an assessment of the overall state of the Arctic environment [52]. However, it was not until 2006 that the Foreign Ministers of the Arctic States approved a proposal to develop a comprehensive assessment, agreeing that it would be a "... major contribution to international conventions and agreements in regard to biodiversity conservation; providing policymakers with comprehensive information on the status and trends of Arctic biodiversity" [53].

The Tromsø Ministerial Declaration reiterated the need for an ABA to improve our understanding of the "... impacts of climate change and other stressors on nature and biodiversity and the adaptability and sustainable use of all living resources in the Arctic" [54] and highlighted its importance as a contribution towards the United Nations 2010 goal to reduce the loss of biodiversity. However, it took four years after the proposal to develop an ABA, was approved before the first component, the Arctic Biodiversity Trends 2010: Selected Indicators of Change report [42], was delivered. This was a preliminary report ahead of the full assessment itself, which the Nuuk Ministerial Declaration [55] emphasized had still not been completed. In 2013, the Arctic Council finally released the ABA [56], highlighting the dramatic consequences of climate change and other factors adversely affecting Arctic species and their habitats, and providing critical information and recommendations to policymakers [1].

Despite unanimous agreement amongst Arctic States and being reflected in three Ministerial Declarations [54-56], it took three years after the ABA proposal was approved to find the resources and capacity to initiate the process and another five before its completion in 2013. That it took the greater part of a decade to complete a unanimously agreed upon, urgent task is not reflective of an efficient approach to harnessing the knowledge and capacity needed to make informed, timely and effective decisions in the face of cumulative and accelerating change [9,57]. As the Arctic faces an ever-increasing rate of change, this delay underscores the need to find ways to speed up and scale up actions to support the sustainable conservation of the Arctic's biodiversity, and to shorten the time between the detection of changes in Arctic ecosystems, and effective policy responses.

In order to keep the baseline created by the ABA up to date, CAFF's Circumpolar Biodiversity Monitoring Programme (CBMP) [58] is implementing a series of ecosystem-based monitoring plans [59-62] to compile, harmonize and compare results from existing Arctic biodiversity and ecosystem monitoring efforts. Each plan identifies key elements, Focal Ecosystem Components (FEC), where changes in their status likely indicate changes in the overall environment [58]. The first outcomes from the implementation of these plans are a series of State of Arctic Biodiversity Reports [55,63], which respond to ABA recommendations on the need to fill gaps in knowledge and detect trends [1]. These reports reflect a move towards more coordinated and integrated reporting on biodiversity by the Council.

\subsection{Developing Key Findings and Recommendations}

The ABA was an essential first step in developing a foundation to support informed decision making. However, a 678-page document is not easily digested and ensuring its findings and recommendations might be understood and acted upon required a distilling of its key messages into a form that was more readily understood and less technical. Therefore, upon completion of the scientific assessment, the experts involved summarised its findings and identified a suite of suggested conservation and research priorities [64]. Informed by these priorities, the Arctic states, in consultation with the indigenous organizations who are members of the Council and assisted by the ABA Chief Scientist [65], negotiated nine key findings and seventeen policy recommendations designed to act on these findings. As part of this process, recommendations from all Arctic Council initiatives were also reviewed to ensure that the ABA recommendations, while they may sometimes overlap, are also mutually supportive [15]. It is interesting to note that the conservation and research priorities are more far reaching than the policy recommendations, but are not tracked or reflected in reporting on the status of implementation of the ABA recommendations, reflecting an oversight on how the outcomes of the ABA have been addressed. 
These seventeen recommendations for policymakers (Table 1) are directed to the Arctic Council as a whole, and while some are intended to be implemented through CAFF, others are intended to be addressed via other Arctic Council subsidiary bodies, while others still require action by national/sub-national authorities, stakeholders, non-Arctic States and international organizations [15]. Upon approval of the policy recommendations at the 2013 Kiruna meeting of the Foreign Ministers of the Arctic States [56] the Arctic Council had, for the first time, a comprehensive framework identifying the issues affecting biodiversity and an agreement about where action was needed.

Table 1. Arctic Biodiversity Assessment (ABA) Recommendations [1].

\begin{tabular}{|c|c|}
\hline \multicolumn{2}{|c|}{ Climate Change } \\
\hline 1 & $\begin{array}{l}\text { Actively support international efforts addressing climate change, both reducing stressors and } \\
\text { implementing adaptation measures, as an urgent matter. }\end{array}$ \\
\hline 2 & $\begin{array}{l}\text { Incorporate resilience and adaptation of biodiversity to climate change into plans for development } \\
\text { in the Arctic. }\end{array}$ \\
\hline \multicolumn{2}{|c|}{ Ecosystem-based management } \\
\hline 3 & $\begin{array}{l}\text { Advance and advocate ecosystem-based management efforts in the Arctic as a framework for } \\
\text { cooperation, planning and development. }\end{array}$ \\
\hline \multicolumn{2}{|c|}{ Mainstreaming biodiversity } \\
\hline 4 & $\begin{array}{l}\text { Require the incorporation of biodiversity objectives and provisions into all Arctic Council work and } \\
\text { encourage the same for on-going and future international standards, agreements, plans, operations } \\
\text { and/or other tools specific to development in the Arctic. }\end{array}$ \\
\hline \multicolumn{2}{|c|}{ Identifying and safeguarding important areas for biodiversity } \\
\hline 5 & $\begin{array}{l}\text { Advance the protection of large areas of ecologically important marine, terrestrial and freshwater } \\
\text { habitats, taking into account ecological resilience in a changing climate. }\end{array}$ \\
\hline 6 & $\begin{array}{l}\text { Develop guidelines and implement appropriate spatial and temporal measures where necessary to } \\
\text { reduce human disturbance to areas critical for sensitive life stages of Arctic species that are outside } \\
\text { protected areas, for example along transportation corridors. }\end{array}$ \\
\hline 7 & $\begin{array}{l}\text { Develop and implement mechanisms that best safeguard Arctic biodiversity under changing } \\
\text { environmental conditions, such as loss of sea ice, glaciers and permafrost. }\end{array}$ \\
\hline \multicolumn{2}{|c|}{ Addressing individual stressors on biodiversity } \\
\hline 8 & $\begin{array}{l}\text { Reduce stressors on migratory species range-wide, including habitat degradation and } \\
\text { overharvesting on wintering and staging areas and along flyways and other migration routes. }\end{array}$ \\
\hline 9 & $\begin{array}{l}\text { Reduce the threat of invasive alien/non-native species to the Arctic by developing and implementing } \\
\text { common measures for early detection and reporting, identifying and blocking pathways of } \\
\text { introduction, and sharing best practices and techniques for monitoring, eradication and control. }\end{array}$ \\
\hline 10 & Promote the sustainable management of the Arctic's living resources and their habitat. \\
\hline 11 & Reduce the threat of pollutants to Arctic biodiversity. \\
\hline \multicolumn{2}{|c|}{ Improving knowledge and public awareness } \\
\hline 12 & $\begin{array}{l}\text { Evaluate the range of services provided by Arctic biodiversity in order to determine the costs } \\
\text { associated with biodiversity loss and the value of effective conservation in order to assess change } \\
\text { and support improved decision making. }\end{array}$ \\
\hline 13 & $\begin{array}{l}\text { Increase and focus inventory, long-term monitoring and research efforts to address key gaps in } \\
\text { scientific knowledge identified in this assessment to better facilitate the development and } \\
\text { implementation of conservation and management strategies. }\end{array}$ \\
\hline 14 & $\begin{array}{l}\text { Recognize the value of traditional ecological knowledge and work to further integrate it into the } \\
\text { assessment, planning and management of Arctic biodiversity. }\end{array}$ \\
\hline 15 & $\begin{array}{l}\text { Promote public training, education and community-based monitoring, where appropriate, as } \\
\text { integral elements in conservation and management. }\end{array}$ \\
\hline 16 & $\begin{array}{l}\text { Research and monitor individual and cumulative effects of stressors and drivers of relevance to } \\
\text { biodiversity, with a focus on stressors that are expected to have rapid and significant impacts and } \\
\text { issues where knowledge is lacking. }\end{array}$ \\
\hline 17 & $\begin{array}{l}\text { Develop communication and outreach tools and methodologies to better convey the importance and } \\
\text { value of Arctic biodiversity and the changes it is undergoing. }\end{array}$ \\
\hline
\end{tabular}




\subsection{Creating a Framework to Guide Implementation}

A challenge facing some Arctic Council products is that, upon delivery of a report or assessment, no plan for implementing findings or recommendations may be asked for, leading to the lack of a framework to guide and report on follow-up actions. For example, in the case of the Arctic Human Development Reports [66,67], the lack of a clear set of approved policy recommendations hindered how they might have helped frame the work of the Council with regards to sustainable development [9]. However, upon approving the ABA recommendations, the foreign ministers of the Arctic states also encouraged Arctic states to follow-up on the recommendations, and (importantly) instructed the Senior Arctic Officials (SAOs) to develop a plan to support and implement its recommendations and deliver a progress report to the next ministerial meeting [56].

In response, CAFF developed the Actions for Biodiversity [15], which entailed each ABA recommendation being analysed to identify gaps and implementation options, with all Arctic Council subsidiary bodies reviewing their activities and indicating how they have or would respond to the recommendations. A broader realm of stakeholders were engaged through the first Arctic Biodiversity Congress [68], where participants had opportunities to advise on the development of the Actions for Biodiversity [15]. For each recommendation, a series of actions were then defined that need to be accomplished in order for a recommendation to have an impact upon the issue it was designed to address.

The Actions for Biodiversity are organized into two-year implementation periods, corresponding to the cycle of rotation of the Arctic Council and Working Group chairmanships, with each period finishing at a Ministerial Meeting where the focus and deliverables for the next phase are reviewed. This was designed to help align priorities, resource allocation, and reporting, thus smoothing the groundwork for implementation. The current Actions for Biodiversity are scheduled to be completed in 2021, with a final report, including new Actions for Biodiversity, to be delivered to the foreign ministers of the Arctic states in 2021.

While the Council as a whole does not yet have a strategic plan, for the first time it now has a clear overarching framework to guide and inform its actions on biodiversity, and to align these actions within the broader global biodiversity frameworks, e.g., the upcoming Post-2020 global biodiversity framework. Furthermore, the structure of the Actions for Biodiversity has provided a means of tracing the path between a Council recommendation and an effective response, thus increasing the visibility of Council effectiveness, and better connecting disparate actions into an overall strategic direction. This provides a reporting mechanism and a potential framework to facilitate evaluation of the effectiveness of the Council's biodiversity activities. However, in the absence of obligated reporting, a challenge remains to ensure that follow-up progress reports are conducted and that the gaps and challenges identified in this reporting process are acted upon.

\subsection{Reporting on Implementation}

In order to understand if a recommendation has had a positive impact on the issues it was created to address, certain minimum criteria need to be met: (1) an activity needs to be initiated in response to the recommendation; (2) the design of the activity should include a means to evaluate outcomes; and (3) these outcomes and evaluation should be reported within the Council. The Actions for Biodiversity go some way towards meeting these criteria in that they provide the means to track what actions are being taken in response to each $\mathrm{ABA}$ recommendation and contains a reporting and evaluation component. However, the utility of the current Actions for Biodiversity is limited in that the overview it provides is of initiatives taken by the Council itself and, except for isolated examples, does not capture how or if the behaviour of Arctic Council states, Permanent Participants and/or Observers might have changed in response to recommendations.

The reporting framework for the Actions for Biodiversity comprise annual reports on progress towards implementation; biennial reports providing a more in-depth evaluation to review progress and make revisions as needed; and a final report, which will include recommendations for follow-up, 
to be delivered at the Arctic Council Ministerial Meeting in 2021. Thus far two biennial progress reports have been delivered to the Foreign Ministers of the Arctic Council [20,21] and regular reports delivered to the CAFF Board [69] providing a status on implementation of tasks described in the Actions for Biodiversity. In addition, progress reports have been developed for three CAFF programmes which are key to the implementation of the Actions for Biodiversity, i.e., the CBMP [70], Arctic Migratory Birds Initiative (AMBI) [71], and Arctic Biodiversity Data Service (ABDS) [72,73].

Given CAFF's role as a mechanism to develop common responses on issues of importance for Arctic biodiversity and ecosystems [28], the implementation of the Actions for Biodiversity could serve an important function in reporting on progress in the Arctic towards achieving global biodiversity targets, e.g., Aichi Targets, the Sustainable Development Goals (SDG), and the new Post-2020 Global Biodiversity Framework currently under development. To explore this potential, the ABA recommendations were mapped by CAFF against the Aichi Targets and the SDGs, which found that CAFF activities relate most directly to SDGs 14,15 and 17 as well as several targets within SDGs 6 , 11-13 and most Aichi Targets [74].

\subsection{Status of Implementation}

In reporting on the Actions for Biodiversity, each action was assigned a status (initiated; not started; planned; completed) indicating if implementation was underway, which might result in steps towards the achievement of a recommendation (Figure 2). In order to assign a status to them, Arctic Council reports were reviewed and experts queried. Outcomes underwent a review by Arctic Council Working Groups and representatives of Arctic states and permanent participants. There are currently 124 implementation actions defined in the Actions for Biodiversity, an increase of 17 from 2013, and of these:

- Seventy-six have been initiated and are ongoing;

- Fourteen planned for 2013-2019 have not started;

- Seven are scheduled to begin between 2019 and 2023;

- Twenty-seven have been completed.

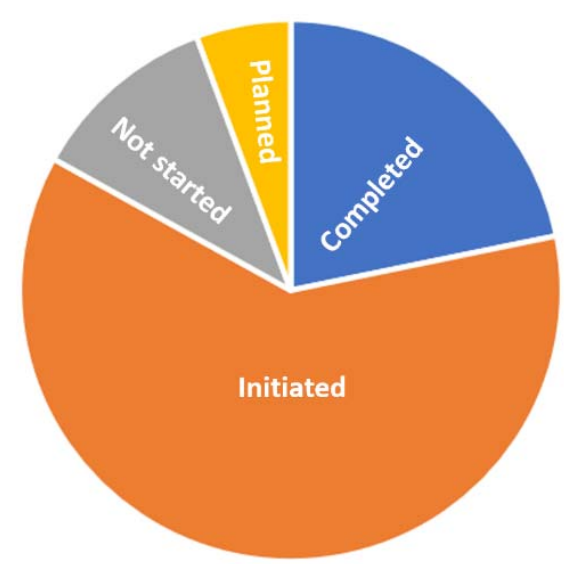

Figure 2. Status of ABA implementation actions 2013-2019.

Failure to initiate a task(s) was determined to be due to one or more of the following factors: no leads, a lack of funding and/or changing priorities. The progress report on ABA implementation delivered to the 2019 Arctic Council ministerial meeting contains details on the status of implementation for each task [21]. 


\section{Discussion}

\subsection{Mechanisms of Influence}

Delivering policy recommendations and advice for management are key to how the Council draws attention to issues of concern. Through the identification of actions needed in response, e.g., as in the Actions for Biodiversity, the Council can nudge states and others towards necessary changes in behaviour. However, reporting on the Actions for Biodiversity in terms of whether tasks have been initiated only reflects those issues and actions that states are willing to address collectively within the context of the Council. It does not capture changes in behaviour by individual states, for example, in state policy or regulations in response to a recommendation. What the progress reports $[20,21]$ do begin to highlight is how, despite its lack of formal authority and resources to directly engage in implementation, the Council can influence behaviour and nudge movement towards the desired actions through knowledge building, facilitating dialogue, enhancing capacity, making data accessible, supporting regional and global frameworks, and providing advice to decision makers. Such mechanisms can be viewed as an exercise in "soft power" and are often overlooked by those who think in terms of formal authority or material resources, but can be key in ensuring change occurs. However, they are not always effective and a consideration of how they are deployed by the Council can help tease out the conditions that are conducive to success in exercising such soft power.

Building knowledge through monitoring and assessment is a core activity of the Council where it has received widespread recognition as a credible and legitimate source on the challenges being faced in the Arctic [48,75]. This mechanism can sometimes trigger political action, with the Arctic Climate Impact Assessment [76] being perhaps the most well-known example of the potential a Council assessment has to influence change. A more recent example is how cooperation between states engaged in the implementation of CAFF's Arctic Marine Biodiversity Monitoring Plan [62] led to the identification of time and cost-effective possibilities for marine benthos monitoring. This resulted in a benthic biodiversity monitoring component being added to the existing annual monitoring process for commercial fish-stocks in several Arctic countries (Greenland, Iceland and Norway), thus improving the coverage of overall biodiversity monitoring with relatively little extra cost [20]. This synergy might seem simple, but may not have occurred, without the Council's recognition of a gap in knowledge and subsequent investment by Arctic states to facilitate the gathering and exchange of knowledge [9].

Other important influence mechanisms are the efforts to facilitate and increase engagement with Arctic biodiversity among diverse stakeholders on different scales. This can be seen in how the Council is responding to a key challenge, i.e., accommodating the desires of observer states and organisations for greater involvement, while retaining Arctic state sovereignty. Its ability to do so will have consequences in terms of access to resources, knowledge, and how states and bodies outside the Council respond to and act upon its products [9]. Migratory species are an obvious issue in which to engage with non-Arctic states and CAFF's Arctic Migratory Birds Initiative (AMBI) has become a test case through which the Council is exploring a model for how to do so. Under AMBI, for the first time, the Council is recommending specific actions to be taken outside of the Arctic in order to help conserve Arctic species [77]. This allows Arctic Council observer states to directly contribute to the Council's work within their own jurisdictions, thus fulfilling the ABA recommendations as well as the requirement for observer states to engage with the Council at the Working Group level [73]. The impact of these efforts is reflected in the significant increase in the numbers of organizations and non-Arctic states involved in AMBI. Over 70 organizations, including governments, academia, industry and NGOs from 20 non-Arctic states have been engaged, ranging from attending or hosting meetings, membership on flyway committees and providing resources. Prior to this, observer state engagement in CAFF was limited, and this increased cooperation reflects a growing understanding that the implementation of some ABA recommendations requires action by and partnership between Arctic and non-Arctic states, stakeholders, and international organizations, thereby strengthening the role of the Arctic Council and fulfilling various Arctic Council priorities. 
Facilitating engagement within the Council itself is also an important task and a perceived lack of cooperation across its subsidiary bodies is often cited in the literature on the Council (e.g., [47,78]). The reporting and evaluation component built into the Actions for Biodiversity is an example of how cooperation across Arctic Council subsidiary bodies can be encouraged, with all subsidiary bodies involved in the design of the plan and reporting on its implementation. Increasing engagement can also be seen in the growing number of cross-cutting initiatives between subsidiary bodies working on tasks identified in the Actions for Biodiversity. Cross-cutting tasks focused initially on technical issues, e.g., as in the pooling of expertise to identify areas of heightened sensitivity to shipping [79], but have begun to evolve to include co-led policy-orientated activities, such as the development of the Arctic Invasive Alien Species Strategy and Action Plan (ARIAS) [80] and cooperation on the Arctic Marine Protected Areas Framework [81].

Enhancing the capacity of the Council is challenging to achieve, given the limited resources available. However, opportunities are provided for relevant stakeholders to join Council activities, learn how the system operates, and to take these skills back to inform their organisations. Examples include the science-policy fellowship developed by CAFF and the International Arctic Science Committee (IASC), supported by the Association of Polar Early Career Scientists (APECS), where early career scientists are recruited to join a CAFF initiative and become involved in the process of conducting research and developing a product to inform decision making [82]. Furthermore, reflecting an urgency to include youth in the Council's work, CAFF and WWF organised the first Arctic Youth Summit, engaging youth from around the world to raise awareness about the Arctic environment, share knowledge, promote conservation and sustainable development, and empower young people [83]. CAFF's youth exchange programme also provides opportunities for young people to spend time in different parts of the Arctic, and contributed to the establishment of the global Arctic Youth Network [84] which has become a presence at Arctic Council meetings, engaging both with SAOs and ministers.

Making information on Arctic biodiversity accessible is an important mechanism in contributing to increased awareness of Arctic biodiversity. It is clear from the growth in visits to CAFF websites, social media followers and numbers of events that the overall trend is one of increasing traffic and dissemination, with peaks occurring around the Arctic Biodiversity Congresses in 2014 [68] and 2018 [85], demonstrating the utility of such events in Arctic Council communication efforts (Figure 3). The Biodiversity Congresses held in conjunction with meetings of the Environment Ministers of the Arctic States have come to play a key role in Arctic Council outreach and are an important tool in both increasing engagement and facilitating dialogue with scientists, indigenous peoples, policymakers, government officials, industry, students, and civil society [6]. Other examples can be seen in efforts to facilitate the mainstreaming of biodiversity, through strengthening and developing the incorporation of biodiversity provisions into the mining industry [86], and how CAFF, through its framework of agreements, supports global biodiversity frameworks, a role that can influence how these fora act on Arctic biodiversity issues. The dramatic increase in numbers of biodiversity data records available from 2015 (Figure 3) reflects the growing capacity of the ABDS to facilitate archiving and access to biodiversity information [72,73]. The recognition of the ABDS as an Arctic node within the United Nations Educational, Scientific and Cultural Organizations (UNESCO) Ocean Biogeographic Information System (OBIS) and the Global Biodiversity Information Facility (GBIF) reflects an increasing awareness of the Council as a provider of data and knowledge on Arctic biodiversity. 

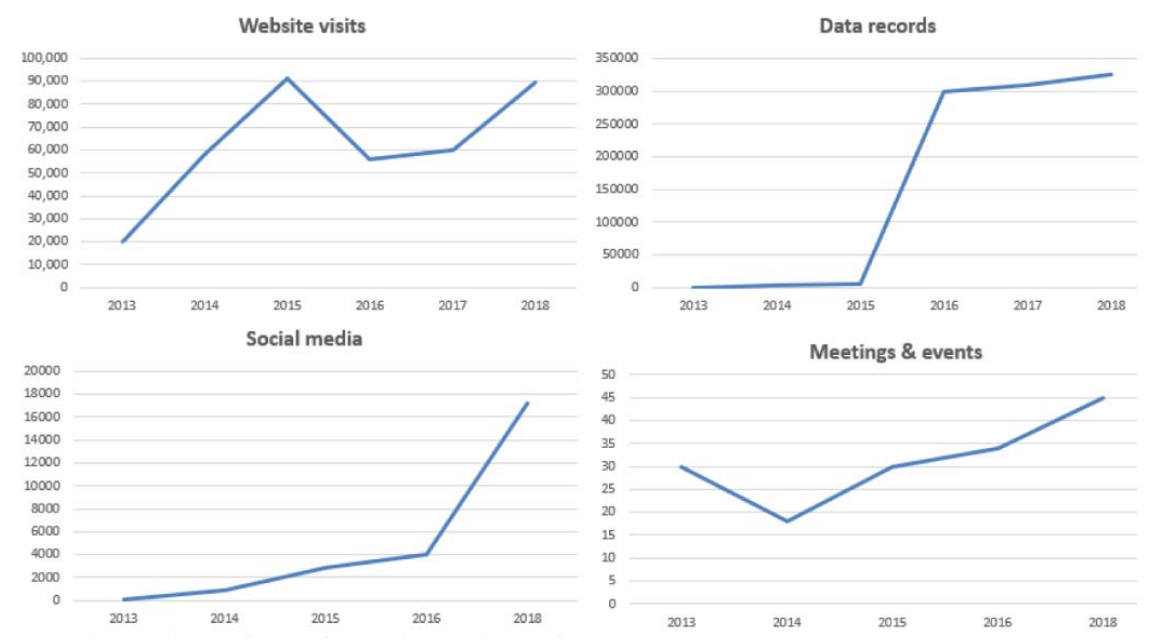

Figure 3. Engagement with CAFF 2013-2018.

\subsection{Making a Difference?}

Through development of the ABA and its implementation plan, the Council has created a means to more effectively guide its activities and decision making concerning biodiversity. While it is easy to map progress on developing outputs such as the ABA [20,21], CBMP [68] and AMBI [71], detecting changes in behaviour in response is more challenging. However, examples can be found, which illustrate how some states are taking steps towards behavioural change in response to Council calls for action on biodiversity issues. For example, the US, in response to the State of the Arctic Marine Biodiversity Report [63], are engaged in a process to improve coordination and planning between state agencies on how they act upon the report's findings and advice. This is an encouraging sign of Council outputs helping nudge movements by a state towards desired actions. However, if the results of such processes do not contribute to resolving the underlying issues being addressed, then, ultimately, they will have failed.

The mechanisms described in Section 4.1, through which the Council can exert influence, can seem nebulous and it is often difficult to draw clear lines between efforts to build knowledge and facilitate dialogue and on the ground change, where clear benefits to biodiversity can be confirmed. However, it is possible to identify examples which illustrate the importance of recording such impacts, helping to highlight the relevance of the Council. For example, during the 1980s and 1990s, declines in eider populations were reported in Canada, Russia, Greenland, and Alaska, e.g., in west Greenland an $80 \%$ reduction in breeding numbers was recorded between 1960 and 2000 [87]. In response, CAFF's Circumpolar Seabird Expert group (CBird) facilitated the development of a population model, demonstrating that harvest levels were unsustainable and should be reduced to halt declines [88]. These findings, supported by actions defined in the Circumpolar Eider Conservation Strategy and Action Plan [89], provided arguments in Greenland that led to modified harvest regulations to restrict the hunting season and the establishment of a community-based monitoring program. As a result, some eider populations began to recover and human disturbance and egging in breeding colonies was reduced [88]. More recent work facilitated by CBird entailed the development of a harvest model for thick-billed murre, quantifying the impacts of hunting and oil pollution in one country on the breeding population in other countries [90]. As a result, Canada, Greenland, Iceland and Norway have begun to discuss an international management plan for the thick-billed murre. Such examples demonstrate how the Arctic Council can contribute towards direct changes in conservation and management practices for Arctic biodiversity.

Another example can be found in the East Asian-Australasian Flyway, where states along the flyway had not managed to find a way to address illegal hunting and unsustainable harvest, one of the key challenges in the conservation of Arctic migratory birds along the Flyway [77]. CAFF's AMBI facilitated the creation of a Task Force on the Illegal Hunting, Taking and Trade of Migratory Waterbirds 
under the auspices of the East Asian-Australasian Flyway Partnership (EAAFP). Prior to AMBI's role in facilitation, states did not systematically address this issue under this cooperative mechanism, despite recognition that illegal hunting was a key threat. It remains to be seen how effective this taskforce may be, but there now exists a means to address this issue, one which would not have existed without the intervention of the Council. Again, this demonstrates the potential for change that the Council can exert. Equally, there are examples where actions in response to ABA recommendations have, following the same recipe, not yielded comparable success, e.g., ARIAS [80], where, three years after its approval, the Council has taken no action as of yet to implement its goals and objectives. This may be reflective of the inability of states to collectively agree on how to implement the ARIAS Strategy and Action Plan or it may just be that a lack of reporting is making it difficult to link relevant actions inside national jurisdictions to ARIAS.

The implementation of policy recommendations is challenging and the literature focused on how this might be achieved is diverse [22,91-94] and it identifies obstacles along the journey from policy to on the ground change (e.g., $[95,96])$. A lack of response to Council recommendations may be due to the need for improved coordination between differing national agencies on their positions across subsidiary bodies of the Council, or it may be that those agencies who have the legal authority to act on Council recommendations are not aware of or engaged in their development. A lack of direct relationships and distance between the Council and the multiple actors who might be expected to act on its recommendations may also contribute to challenges in implementation. Clarity in terms of how recommendations are worded may also influence how or whether recommendations are acted upon. The more ambiguous the wording, then the more challenging it may be for implementing bodies to understand how they might be expected to act in response. ABA recommendations are a mix of specific directions as to what is needed, i.e., to develop and implement joint management and recovery plans for threatened species, while others are more ambiguous, reflecting a need to tackle an issue without specifying how, e.g., to actively support international efforts addressing climate change. Given the complex patterns of causality involved, it can be difficult to pinpoint exact reasons why a response has not been effective or why an action has not been taken. However, a key ingredient often overlooked is leadership-having the right person in the right place at the right time with the passion and skills to make a difference.

\section{Conclusions}

The Arctic Council is undergoing changes in how it operates [9], while, at the same time, the Arctic is facing growing ecological challenges. At this critical juncture, identifying where the Council's activities have had impacts on biodiversity and uncovering the mechanisms through which they were successful may provide an insight into how the Arctic Council can be an agent of change during these ecological crises and inform discussions on its future. The mechanisms used to exercise the soft power described in this paper-knowledge building, facilitating dialogue, enhancing capacity, making data accessible, supporting regional and global frameworks and providing advice to decision makers-play important roles in how the Council works to influence change. We must keep in mind that, as multiple causal factors are often involved in shaping outcomes, it can be difficult to trace the role a Council activity might have played in ensuring a specific outcome.

The Actions for Biodiversity provide a means to evaluate and guide the Council's work on biodiversity and help focus the Council's efforts to influence change. It has resulted in a more coordinated approach by the Council on how it follows up on its biodiversity recommendations. While the absence of obligated reporting makes it difficult to pinpoint where the ABA has had a direct impact, the examples provided, e.g., the role played by the CBMP in filling knowledge gaps and raising awareness, illustrate how the implementation of Council recommendations in tandem with the influence mechanisms described above can play an important role in conserving Arctic biodiversity. While the Actions for Biodiversity have been effective in focusing attention on the importance of implementation and follow-up reporting, it is also clear that, when it comes to taking the jump from 
knowledge to action, the tools or willingness to translate this into action at the national level are often missing $[9,48]$. The Council can also suffer from a lack of forward planning, in that attention can be focused on a product itself, without enough thought given to structure and planning to ensure follow ups on its findings [9] in order to facilitate clear reporting and an evaluation of responses. A more thorough understanding of how the Council's activities have been used and acted upon in global, national, and more local contexts will require more comprehensive reporting within the Council by member states and organisations.

As the Arctic Council approaches its 25th anniversary, its purpose and role in Arctic governance is increasingly under scrutiny (e.g., [97]). Therefore, as it reaches this milestone, establishing a robust means of reporting on the outcomes of its activities and evaluating their effectiveness would be an important contribution towards demonstrating the relevance of the Council, facilitating the setting of priorities for its work, and shedding light on potential roles the Council might play in the increasingly complex framework of Arctic governance. While this paper has focused on just one aspect of the Council's, work similar attention paid to other areas within its broad range of activities would help inform discussions on the future of the Council.

Author Contributions: Conceptualization, T.B., B.D., N.E. and O.R.Y.; formal analysis, T.B.; investigation, T.B.; methodology, T.B.; project administration, T.B.; supervision, B.D., N.E. and O.R.Y.; writing-original draft, T.B.; writing-review \& editing, T.B., B.D., N.E. and O.R.Y. All authors have read and agree to the published version of the manuscript.

Funding: This research received no external funding.

Acknowledgments: We thank the numerous people who took time to review this paper and provide insights and constructive comments which led to its improvement. This work is supported by, and contributes to, the NordForsk-funded Nordic Centre of Excellence project (award 76654) Arctic Climate Predictions: Pathways to Resilient, Sustainable Societies (ARCPATH).

Conflicts of Interest: The corresponding author is employed (2008-present) within the Arctic Council, which is the organisation considered within this article.

\section{Abbreviations}

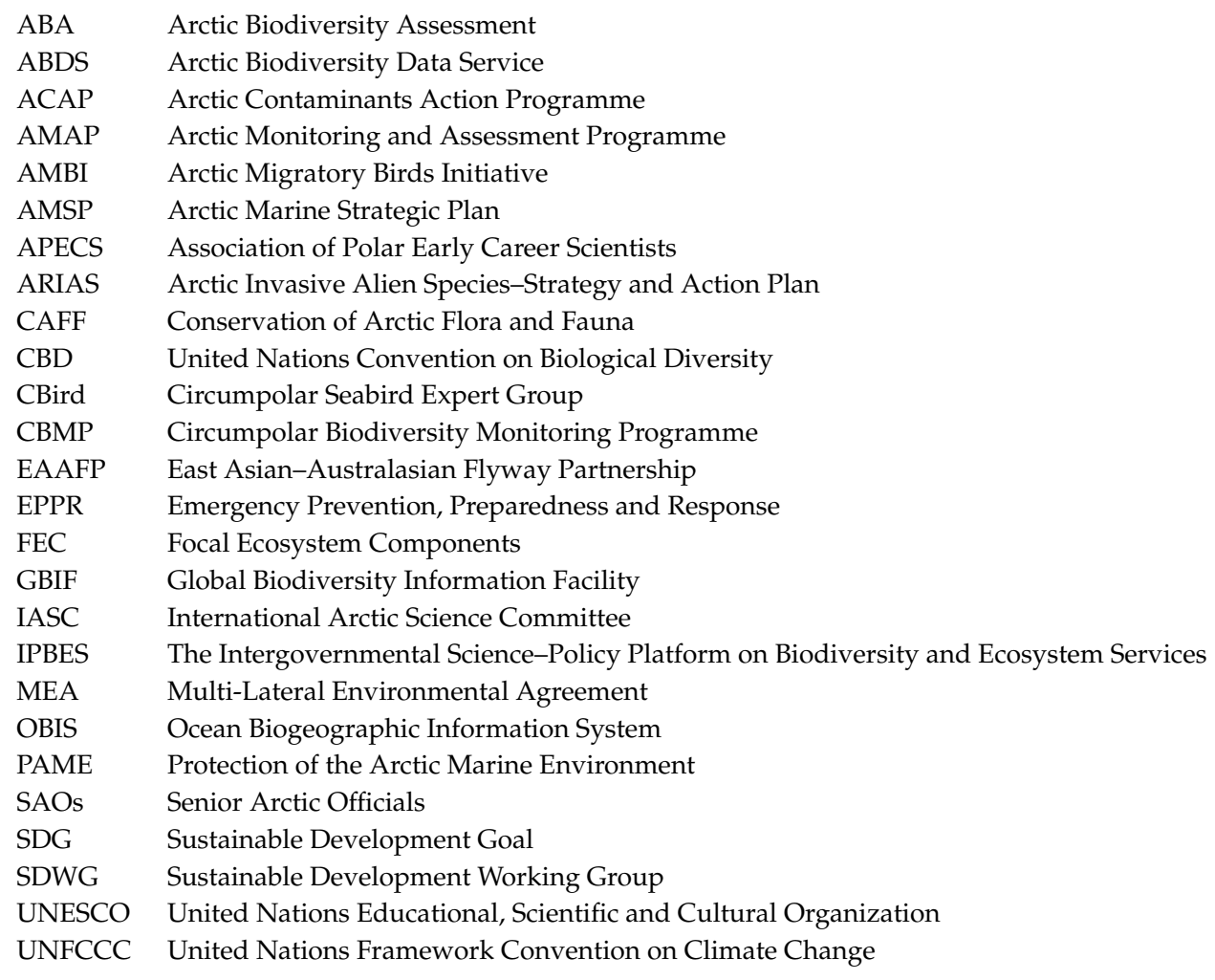




\section{References}

1. CAFF. Arctic Biodiversity Assessment: Report for Policy Makers; CAFF International Secretariat: Akureyri, Iceland, 2013; pp. 1-28.

2. IPPC. Summary for Policymakers. In IPCC Special Report on the Ocean and Cryosphere in a Changing Climate'; Pörtner, H.-O., Roberts, D.C., Masson-Delmotte, V., Zhai, P., Tignor, M., Poloczanska, E., Mintenbeck, K., Alegría, A., Nicolai, M., Okem, A., et al., Eds.; IPCC Secretariat: Geneva, Switzerland, 2019.

3. Taylor, J.J.; Lawler, P.M.; Aronsson, M.; Barry, T.; Bjorkman, A.D.; Christensen, T.; Coulson, S.J.; Cuyler, C.; Ehrich, D.; Falk, K.; et al. Arctic terrestrial biodiversity status and trends: A synopsis of science supporting the CBMP State of Arctic Terrestrial Biodiversity Report'. Ambio 2020, 49, 833-847. [CrossRef] [PubMed]

4. Lento, J.; Goedkoop, W.; Culp, J.; Christoffersen, K.S.; Lárusson, K.F.; Fefilova, E.; Guðbergsson, G.; Liljaniemi, P.; Ólafsson, J.S.; Sandøy, S.; et al. State of the Arctic Freshwater Biodiversity; Conservation of Arctic Flora and Fauna International Secretariat: Akureyri, Iceland, 2019; pp. 1-124.

5. CAFF. State of the Arctic Marine Biodiversity: Key Findings and Advice for Monitoring; Conservation of Arctic Flora and Fauna International Secretariat: Akureyri, Iceland, 2017; pp. 1-22.

6. Smith, R.; Barry, T.; Kateras, F. Thoughts on the Arctic Biodiversity Congress. Biodiversity 2015, 16, 47-50. [CrossRef]

7. Arctic Council. 1996 Ottawa Declaration, Arctic Council Secretariat. 1996. Available online: http: //hdl.handle.net/11374/85 (accessed on 1 May 2020).

8. Arctic Council. Arctic Council Rules of Procedure; Arctic Council: Tromsø, Norway, 2013; pp. 1-16; Available online: http://hdl.handle.net/11374/940 (accessed on 1 May 2020).

9. Barry, T.; Daviðsdóttir, B.; Einarsson Young, O. The Arctic Council: An Agent of Change? Glob. Environ. Chang. 2020, 63. [CrossRef]

10. CBD. UN Convention on Biological Diversity (CBD): Decision X/13 New and Emerging Issues. 2010. Available online: https://www.cbd.int/decision/cop/?id=12279 (accessed on 11 January 2020).

11. CAFF. Arctic Biodiversity and the Post2020 Framework, Report Submitted to the Chairs of the Open-Ended Working Group on the Post-2020 Global Biodiversity Framework on Its Second Meeting; CAFF International Secretariat: Akureyri, Iceland, 2020; pp. 1-13.

12. Johnstone, R.L. Offshore Oil and Gas Development in the Arctic under International Law: Risk and Responsibility; Queen Mary Studies in International Law; Martinus Nijhoff Publishers: Leiden, The Netherlands, 2015; Volume 14, ISBN 978-90-04-26933.

13. ACAP. ACAP Strategy to Address Contamination of the Arctic Environment and its People; Arctic Council Secretariat: Tromsø, Norway, 2016; pp. 1-4.

14. AMAP. Strategic Framework 2019+; Arctic Monitoring and Assessment Programme (AMAP): Tromsø, Norway, 2019; pp. 1-8.

15. CAFF. Actions for Arctic Biodiversity, 2013-2021: Implementing the Recommendations of the Arctic Biodiversity Assessment; CAFF International Secretariat: Akureyri, Iceland, 2015; pp. 1-32.

16. EPPR. EPPR Strategic Plan of Action; Arctic Council Secretariat: Tromsø, Norway, 2016; pp. 1-5.

17. PAME. Arctic Marine Strategic Plan 2015-2025: Protecting Marine and Coastal Ecosystems in a Changing Arctic; PAME International Secretariat: Akureyri, Iceland, 2015; pp. 1-20.

18. SDWG. The Human Face of the Arctic: Strategic Framework 2017; SDWG Secretariat: Ottawa, ON, Canada, 2017; pp. 1-28.

19. Meltofte, H. (Ed.) Arctic Biodiversity Assessment: Status and Trends in Arctic Biodiversity; CAFF International Secretariat: Akureyri, Iceland, 2013; pp. 1-678.

20. Barry, T. Actions for Biodiversity 2013-2021: Implementing the Recommendations of the ABA. Progress Report 2017; CAFF International Secretariat: Akureyri, Iceland, 2017; pp. 1-10.

21. Barry, T. Actions for Biodiversity 2013-2021: Implementing the Recommendations of the ABA. Progress Report 2019; CAFF International Secretariat: Akureyri, Iceland, 2019; pp. 1-10.

22. Smieszek, G. Evaluating institutional effectiveness: The case of the Arctic Council. Polar J. 2019, 9, 3-26. [CrossRef]

23. Smieszek, G. Steady as She Goes? Structure Change Agents and the Evolution of the Arctic Council. Yearb. Polar Law 2019, 11, 39-80. [CrossRef] 
24. Koivurova, T. The Limits and Possibilities of the Arctic Council in a Rapidly Changing Scene of Arctic Governance; Cambridge University Press: Cambridge, UK, 2019; pp. 146-156.

25. Haavisto, P. Review of the Arctic Council Structures; Publisher: Arctic Council, Norway, 2001; pp. 1-55.

26. Johnston, R. Environmental Governance through the Arctic Council: The Arctic Council as Initiator of Norms of International Environmental Law; PCRC Working Paper No. 1; PCRC: Kobe University, Japan, 2016; pp. 1-23.

27. Duyck, S. What Role for the Arctic in the UN Paris Climate Conference (COP-21). Arct. Yearb. 2015, $2015,1-9$.

28. Chapin, S., III; Sommerkorn, M.; Robards, M.; Hillmer-Pegram, K. Ecosystem stewardship: A resilience framework for arctic conservation. Glob. Environ. Chang. 2015, 34, 207-217. [CrossRef]

29. Koivurova, T. Governance of protected areas in the Arctic. Utrecht Law Review 2009, 5, 44-60. [CrossRef]

30. WWF Arctic Programme. WWF Arctic Council Conservation Scorecard; WWF: Ottawa, ON, Canada, 2017; pp. 1-76.

31. WWF Arctic Programme. WWF Arctic Council Conservation Scorecard: Country Profiles; WWF: Ottawa, ON, Canada, 2019; pp. 1-16.

32. WWF Arctic Programme. WWF Arctic Council Conservation Scorecard 2019: Methodology; WWF: Ottawa, ON, Canada, 2019; pp. 1-16.

33. Arctic Council. Amarok: The Arctic Council tracking tool; Maxi-Report; Arctic Council Secretariat: Tromsø, Norway, 2019; pp. 1-294.

34. CAFF. CAFF Framework Document; CAFF International Secretariat: Akureyri, Iceland, 1996; pp. 1-8.

35. CAFF. Resolution of Cooperation between the Secretariats of the Conservation of Arctic Flora and Fauna and the Convention on Biological Diversity; CAFF International Secretariat: Akureyri, Iceland, 2009; pp. 1-2.

36. CAFF. Resolution of Cooperation between the Secretariats of the Conservation of Arctic Flora and Fauna and the Association of Early Polar Career Scientists; CAFF International Secretariat: Akureyri, Iceland, 2009; pp. 1-2.

37. CAFF. Resolution of Cooperation between the Secretariats of the Conservation of Arctic Flora and Fauna and the Convention on Migratory Species; CAFF International Secretariat: Akureyri, Iceland, 2013; pp. 1-2.

38. CAFF. Resolution of Cooperation between the Secretariats of the Conservation of Arctic Flora and Fauna and the East Asian Australasian Flyway Partnership; CAFF International Secretariat: Akureyri, Iceland, 2013; pp. 1-2.

39. CAFF. Resolution of Cooperation between the Secretariats of the Conservation of Arctic Flora and Fauna and the Ramsar Convention on Wetlands; CAFF International Secretariat: Akureyri, Iceland, 2013; pp. 1-2.

40. CAFF. Resolution of Cooperation between the Secretariats of the Conservation of Arctic Flora and Fauna and the Global Biodiversity Information Facility; CAFF International Secretariat: Akureyri, Iceland, 2016; pp. 1-2.

41. CAFF. Memorandum of Cooperation between the Polar Bear Agreement (PBA) and the Conservation of Arctic Flora and Fauna Working Group (CAFF); CAFF International Secretariat: Akureyri, Iceland, 2019; pp. 1-4.

42. CAFF. Arctic Biodiversity Trends 2010-Selected Indicators of Change; CAFF International Secretariat: Akureyri, Iceland, 2010; pp. 1-124.

43. UN Convention on Biological Diversity (CBD). Decision X/13 New and Emerging Issues; UN Convention on Biological Diversity (CBD): Montreal, QC, Canada, 2010.

44. UN Convention on Biological Diversity (CBD). Decision XI/6/D. Collaboration on Arctic Biodiversity; UN Convention on Biological Diversity (CBD): Montreal, QC, Canada, 2012.

45. CAFF. Arctic Biodiversity status and trends, report submitted to the Tenth Meeting of the Parties to the Convention on Biological Diversity 2010; CAFF International Secretariat: Akureyri, Iceland, 2010.

46. Böhm, M.; McRae, L.; Deinet, S.; Gill, M.; Collen, B. Tracking Trends in Arctic Vertebrate Populations through Space and Time; CAFF Assessment Series No. 8; Conservation of Arctic Flora and Fauna: Akureyri, Iceland, 2012; pp. 1-42.

47. Environment Canada. Canada's 5th National Report to the Convention on Biological Diversity; Environment Canada: Ottawa, ON, Canada, 2014; pp. 1-112.

48. Prip, C. The Arctic Council and biodiversity-need for a stronger management framework? Nord. Miljörättslig Tidskr. Nordic Environ. Law J. 2016, 2, 1-19.

49. Barry, T.; Price, C. Arctic biodiversity: From science to policy. J. Environ. Stud. Sci. 2015, 5, $283-287$. [CrossRef]

50. Kankaanpää, P.; Smieszek, M. (Eds.) Assessments in Policy-Making: Case Studies from the Arctic Council. Preparatory Action, Strategic Environmental Impact Assessment of Development of the Arctic; Arctic Centre, University of Lapland: Lapland, Finland, 2014; pp. 74-76. 
51. Rottem, S.V. The Arctic Council: Vision, Structure, and Participation; Fridtjof Nansen Institute: Lysaker, Norway, 2016; pp. 1-19.

52. CAFF. Arctic Flora and Fauna: Status and Conservation; CAFF: Akureyri, Iceland, 2001; pp. 1-266.

53. Arctic Council. The Salekhard Declaration: The Fifth Ministerial Meeting of The Arctic Council; Arctic Council Secretariat: Tromsø, Norway, 2006; p. 7.

54. Arctic Council. Tromsø Declaration: The Sixth Ministerial Meeting of the Arctic Council; Arctic Council Secretariat: Tromsø, Norway, 2009; p. 7.

55. Arctic Council. Nuuk Declaration: The Seventh Ministerial Meeting of the Arctic Council; Arctic Council Secretariat: Tromsø, Norway, 2011; pp. 1-7.

56. Arctic Council. Kiruna Declaration. The Eight Ministerial Meeting of the Arctic Council; Arctic Council Secretariat: Tromsø, Norway, 2013; pp. 1-9.

57. Fenge, T. The Arctic Council: Past, Present, and Future Prospects with Canada in the Chair from 2013 to 2015. North. Rev. 2013, 37, 7-35.

58. CAFF. Circumpolar Biodiversity Monitoring Program Strategic Plan 2018-2021; CAFF Monitoring Series Report No. 29; CAFF International Secretariat: Akureyri, Iceland, 2018; pp. 1-25.

59. Christensen, T.; Payne, J.; Doyle, M.; Ibarguchi, G.; Taylor, J.; Schmidt, N.M.; Gill, M.; Svoboda, M.; Aronsson, M.; Behe, C.; et al. The Arctic Terrestrial Biodiversity Monitoring Plan; CAFF Monitoring Series Report Nr. 7; CAFF International Secretariat: Akureyri, Iceland, 2013; pp. 1-164.

60. Culp, J.M.; Goedkoop, W.; Lento, J.; Christoffersen, K.S.; Frenzel, S.; Gudbergsson, G.; Liljaniemi, P.; Sandoy, S.; Svoboda, M.; Brittain, J.; et al. The Arctic Freshwater Biodiversity Monitoring Plan; CAFF Monitoring Series Report Nr. 7; CAFF International Secretariat: Akureyri, Iceland, 2012; pp. 1-151.

61. Jones, T.; McLennan, D.; Behe, C.; Arenes, M.; Wesseberg, S.; Sergienko, L.; Harris, C.; Harcharek, Q.; Christensen, T. Arctic Coastal Biodiversity Monitoring Plan; Conservation of Arctic Flora and Fauna International Secretariat: Akureyri, Iceland, 2019; pp. 1-72.

62. Gill, M.; Crane, K.; Hindrum, R.; Arneberg, P.; Bysveen, I.; Denisenko, N.V.; Gofman, V.; Grant-Friedman, A.; Gudmundsson, G.; Hopcroft, R.R.; et al. Arctic Marine Biodiversity Monitoring Plan; CAFF Monitoring Series Report No.3; CAFF International Secretariat: Akureyri, Iceland, 2011; pp. 1-138.

63. CAFF. State of the Arctic Marine Biodiversity Report; CAFF International Secretariat: Akureyri, Iceland, 2017; pp. 1-200.

64. CAFF. Arctic biodiversity assessment: Status and trends in Arctic biodiversity: Synthesis; CAFF International Secretariat: Akureyri, Iceland, 2013; pp. 1-132.

65. Dr. Hans Meltofte, Aarhus University, Denmark.

66. Ministerråd, N. Arctic Human Development Report: Regional Processes and Global Linkages; Nordic Council of Ministers: Copenhagen, Denmark, 2015; pp. 1-507.

67. Stefansson Arctic Institute. Arctic Human Development Report; Stefansson Arctic Institute: Akureyri, Iceland, 2004; pp. 1-235.

68. Arctic Biodiversity Congress. 2014. Available online: https://www.arcticbiodiversity.is/index.php/ congress2014 (accessed on 19 April 2020).

69. The CAFF Board consists of National Representatives from the Environment Ministries/Agencies from each Arctic Council Member State, Including Representatives of Indigenous Peoples' Organizations that Are Permanent Participants to the Council, and Arctic Council Observer Countries and Organizations. Available online: https://caff.is/about-caff (accessed on 1 May 2020).

70. Barry, T.; Christensen, C. Circumpolar Biodiversity Monitoring Programme (CBMP) 2017-2019 Progress Report to the 2019 Arctic Council Ministerial; CAFF International Secretariat: Akureyri, Iceland, 2019; pp. 1-16.

71. Provencher, J.; Yong, D.-L.; Black, A.; Mikander, N.; Syroechkovskiy, E.; Braa, A.; Lanctot, R.; Ekker, M.; Gilchrist, G.; Crockford, N.; et al. Arctic Migratory Birds Initiative Mid-Term Evaluation; CAFF International Secretariat: Akureyri, Iceland, 2017; pp. 1-60.

72. Barry, T.; Helgasson, H.; Larusson, K.F. Arctic Biodiversity Data Service (ABDS) 2015-2017 Progress Report to the 2019 Arctic Council Ministerial; CAFF International Secretariat: Akureyri, Iceland, 2017; pp. 1-6.

73. Barry, T.; Helgasson, H.; Larusson, K.F. Arctic Biodiversity Data Service (ABDS) 2017-2019 Progress Report to the 2019 Arctic Council Ministerial; CAFF International Secretariat: Akureyri, Iceland, 2019; pp. 1-6.

74. CAFF. Memorandum to Senior Arctic Officials: Sustainable Development Goals, Arctic Biodiversity; CAFF International Secretariat: Akureyri, Iceland, 2018; pp. 1-5. 
75. Stokke, O.S. Regime interplay in Arctic shipp.ing governance: Explaining regional niche selection. Int. Environ. 2013, 13, 65-85.

76. AMAP; CAFF; IASC. Arctic Climate Impact Assessment; Cambridge University Press: New York, NY, USA, 2006; pp. 1-1020.

77. CAFF. Arctic Migratory Birds Initiative (AMBI): Workplan 2019-2023; CAFF Strategies Series No. 30; Conservation of Arctic Flora and Fauna: Akureyri, Iceland, 2019; pp. 1-56.

78. Supreme Audit Institutions of Denmark, Norway, The Russian Federation, Sweden and the USA. The Arctic Council: Perspectives on a Changing Arctic, the Council's Work, and Key Challenges. A Joint Memorandum of a Multilateral Audit on the Arctic States' National Authorities' Work with the Arctic Council; Arctic Council: Tromsø, Norway, 2020; pp. 1-37.

79. AMAP/CAFF/SDWG. Identification of Arctic Marine Areas of Heightened Ecological and Cultural Significance: Arctic Marine Shipping Assessment (AMSA) IIC; Arctic Monitoring and Assessment Programme (AMAP): Oslo, Norway, 2013; pp. 1-114.

80. CAFF and PAME. Arctic Invasive Alien Species: Strategy and Action Plan; CAFF International Secretariat and PAME International Secretariats: Akureyri, Iceland, 2017; pp. 1-20.

81. PAME. Framework for a Pan-Arctic Network of Marine Protected Areas; PAME International Secretariat: Akureyri, Iceland, 2020; pp. 1-52.

82. CAFF and IASC. CAFF-IASC 2018 Fellowship Report; CAFF International Secretariat: Akureyri, Iceland, 2019; pp. 1-6.

83. Arctic Youth Summit. Available online: https://www.caff.is/youth-summit (accessed on 15 April 2020).

84. Arctic Youth Network. Available online: https://arcticyouthnetwork.org/ (accessed on 19 April 2020).

85. CAFF. Arctic Biodiversity Congress 2018. Available online: https://www.arcticbiodiversity.is/index.php/ congress (accessed on 9 April 2020).

86. CAFF. Mainstreaming Biodiversity in Arctic Mining: Challenges and Proposed Solutions; CAFF International Secretariat: Akureyri, Iceland, 2019; pp. 1-32.

87. Merkel, F.R. Evidence of population Decline in Common Eiders Breeding in Western Greenland. Arctic 2004, 57, 27-36. [CrossRef]

88. Merkel, F.R. Evidence of Recent Population Recovery in Common Eiders Breeding in Western Greenland. J. Wildl. Manag. 2010, 74, 1869-1874. [CrossRef]

89. CAFF. Circumpolar Eider Conservation Strategy and Action Plan; CAFF International Secretariat: Akureyri, Iceland, 1997; pp. 1-25.

90. Frederiksen, M.; Linnebjerg, J.F.; Merkel, R.M.; Wilhelm, S.I.; Robertson, G.J. Quantifying the relative impact of hunting and oiling on Brünnich's guillemots in the North-west Atlantic. Polar Res. 2019, 38, 3378. [CrossRef]

91. Levy, M. Assessing the Effectiveness of International environmental institutions. Glob. Environ. Chang. 1996, 6, 395-397. [CrossRef]

92. Young, O.R.; Levy, M.A. The Effectiveness of International Environmental Regimes. In The Effectiveness of International Environmental Regimes: Causal Connections and Behavioral Mechanisms; Young, O.R., Ed.; MIT Press: Cambridge, MA, USA, 1999; pp. 1-32.

93. Oberthür, S.; Stokke, O.S. Managing Institutional Complexity: Regime Interplay and Global Environmental Change; MIT Press: Cambridge, MA, USA, 2011; pp. 1-353.

94. Pressman, J.; Wildavsky, A. Implementation: How Great Expectations in Washington Are Dashed in Oakland; Or, Why It's Amazing that Federal Programs Work at All, this being a saga of the Economic Development Administration as Told by Two Sympathetic Observers Who Seek to Build Morals on a Foundation of Ruined Hopes; University of California Press: Berkeley, CA, USA, 1984.

95. Hupe, P.L. The Thesis of Incongruent Implementation: Revisiting Pressman and Wildavsky. Public Policy Adm. 2011, 26, 63-80. [CrossRef] 
96. Balton, D.; Fran, U. A Strategic Plan for the Arctic Council: Recommendations for Moving Forward; The Arctic Initiative of the Belfer Center for Science and International Affairs of Harvard University and the Polar Institute of the Woodrow Wilson International Center for Scholars: Washington, DC, USA, 2019.

97. Young, O.R. Is it a time for a reset in Arctic governance? Sustainability 2019, 11, 4497. [CrossRef]

(C) 2020 by the authors. Licensee MDPI, Basel, Switzerland. This article is an open access article distributed under the terms and conditions of the Creative Commons Attribution (CC BY) license (http://creativecommons.org/licenses/by/4.0/). 